REVIEW

\title{
The eicosanoid cascade: possible role in gliomas and meningiomas
}

\author{
N Nathoo, G H Barnett, M Golubic
}

J Clin Pathol: Mol Pathol 2004;57:6-13

Eicosanoids constitute a large family of biologically active lipid mediators that are produced by two enzyme classes, cyclooxygenases (COX-1 and COX-2) and lipoxygenases (5-LO, 12-LO, and 15-LO). Increasing evidence suggests that in addition to a variety of epithelial malignancies, the two most common types of human brain tumour, gliomas and meningiomas, aberrantly overexpress eicosanoid producing enzymes and release a spectrum of eicosanoids that may promote tumorigenesis and the development of peritumorous brain oedema. Glioma and meningioma cells are killed in vitro and in animal models when exposed to COX-2 and 5-LO inhibitors, and their effectiveness is under investigation in clinical trials for treatment of patients with malignant brain tumours. However, despite research into the role of the eicosanoid cascade in the tumorigenesis of human brain tumours, many important questions remain unanswered. Current and newer agents that specifically target key players of the eicosanoid cascade could change the approach to treating brain tumours, because their benefits may lie in their synergism with conventional cytotoxic treatments and/or with other novel agents targeted against other procarcinogenic pathways.

See end of article for authors' affiliations

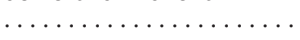

Correspondence to: Dr N Nathoo, Department of Neurosurgery, Cleveland Clinic Foundation, 9500 Euclid Avenue, Cleveland, 44195, Ohio, USA nathoon@ccf.org

Accepted for publication 20 August 2003
$\mathrm{P}$ rimary brain tumours are among the top 10 causes of cancer related death. Approximately 13000 people die from these tumours each year in the USA. ${ }^{1}$ Gliomas and other neuroepithelial tumours make up 49\% of primary brain tumours, and meningiomas are the second most common primary brain tumour $(27 \%)$. $^{2}$

The World Health Organisation (WHO) classifies gliomas as astrocytomas, oligodendrogliomas, and oligoastrocytomas on the basis of the phenotypical resemblance of tumour cells to normal glia (astrocytes or oligodendrocytes, or a combination of both). Astrocytomas are histologically graded as low grade (WHO I and II) and high grade tumours that are classified as anaplastic astrocytoma (WHO III) and glioblastoma multiforme (GBM) (WHO IV), respectively. ${ }^{3}$ The infiltrative growth pattern of high grade gliomas precludes them from being cured by neurosurgery and they respond poorly to other forms of treatment. The median survival of patients with a newly diagnosed GBM has improved only marginally during the past two decades, and today most patients with GBM still die from their disease in less than a year. ${ }^{4}$ In contrast, meningiomas are usually benign tumours that develop from the leptomeningeal cells of the arachnoid membrane that surrounds the brain and spinal cord. ${ }^{5}$ However, they often recur after seemingly complete surgical removal and occasionally progress to a fully malignant phenotype. ${ }^{6}$ Moreover, surgical cure is often not possible in those meningiomas involving the skull base or vital neurovascular structures.

In the past two decades, a large number of molecular and genetic pathways that are altered in brain tumour cells have been identified. ${ }^{4}$ However, the development of novel treatment strategies based on this molecular information has not yet been successfully translated to common clinical practice. A variety of promising drugs that selectively target precise molecular abnormalities, which create and drive the neoplastic phenotype of glioma and meningioma cells, are currently being investigated in clinical trials to improve the survival and quality of life of patients with brain tumours.

\begin{abstract}
"In the past two decades, a large number of molecular and genetic pathways that are altered in brain tumour cells have been identified"
\end{abstract}

In this review, we will discuss the eicosanoid cascade of arachidonic acid (AA) and its relevance to brain tumours, the current evidence for the rationale of using inhibitors of eicosanoid producing enzymes for therapeutic purposes, and the limitations that hinder the full implementation of this form of treatment; in addition, we will suggest future directions for research and clinical practice.

\section{INCREASED CONCENTRATIONS OF AA IN BRAIN TUMOURS}

AA is a $\omega-6$ polyunsaturated fatty acid (PUFA) that is converted into biologically active lipid compounds called eicosanoids. Eicosanoids constitute a large family of biologically active lipid mediators that are produced by two enzyme classes, cyclooxygenases (COX-1 and COX-2) and lipoxygenases (5-LO, 12-LO, and 15-LO)..$^{7-11}$

Abbreviations: $A A$, arachidonic acid; COX, cyclooxygenase; GBM, glioblastoma multiforme; LA, linoleic acid; LO, lipoxygenase; PG, prostaglandin; PLA, phospolipase; PUFA, polyunsaturated fatty acid; WHO, World Health Organisation 
These lipid compounds modulate diverse physiological and pathological processes including carcinogenesis. ${ }^{78}$ Several eicosanoids have been shown to promote cell survival, ${ }^{12-14}$ stimulate cell proliferation, ${ }^{15}{ }^{16}$ and modulate cell adhesion and motility, ${ }^{14}{ }^{16} 17$ angiogenesis, ${ }^{12}{ }^{18}$ increased vascular permeability, ${ }^{19}{ }^{20}$ and inflammation, ${ }^{78}$ thus playing an important role in tumour growth and promotion (fig 1). In the past few years, numerous reports have indicated that not only a variety of epithelial human malignancies, but also glioma and meningioma cells, aberrantly overexpress eicosanoid producing enzymes, release a spectrum of eicosanoids, and are killed when exposed to specific eicosanoid inhibitors.

The importance of AA metabolism in human gliomas and meningiomas has been emphasised by reports demonstrating raised concentrations of $\omega-6$ PUFAs, AA, and its precursor, linoleic acid (LA) in these tumours compared with normal white or grey matter. ${ }^{34-36}$ In contrast, concentrations of $\omega$-3 PUFA docosahexaenoic acid were reduced in glioma samples compared with normal brain samples. ${ }^{35-36}$ These data suggested that the fatty acid composition of human brain tumours is different from that found in non-tumorous brain tissue, with $\omega-6$ PUFAs, which may promote tumorigenesis in brain tumours, being expressed preferentially.
The causes and molecular mechanisms leading to the raised concentrations of LA and AA in gliomas and meningiomas are presently unknown. LA is an essential fatty acid that humans are unable to biosynthesise and is obtained exclusively through dietary intake. ${ }^{37}$ Therefore, it is possible that raised concentrations of LA and AA in brain tumours may be related to high dietary consumption. Even though dietary LA (abundant in oils from various seeds) is the precursor of AA in tissues, dietary AA (exclusive to foods of animal origin) is perhaps the single most important nutritional determinant regulating AA values in humans. ${ }^{38} 39$ Furthermore, Nariai et al demonstrated in a rat tumour model using Walker 256 carcinosarcoma cells that nutritionally relevant fatty acids, including AA, were more readily incorporated into brain tumour tissue than normal brain when administered intravenously. ${ }^{40}$

Epidemiological studies on dietary fat intake and the risk of brain tumours are sparse and not consistent. ${ }^{2}$ Giles et al reported an increased risk of glioma in adult Australians with a high intake of oils, margarine, and salad dressing. ${ }^{41}$ Lubin et al reported that children with brain tumours had a higher consumption of vegetable fat than did controls. ${ }^{42}$ However, no significant association between the risk of glioma and intake of dietary fat was reported in a recent study from

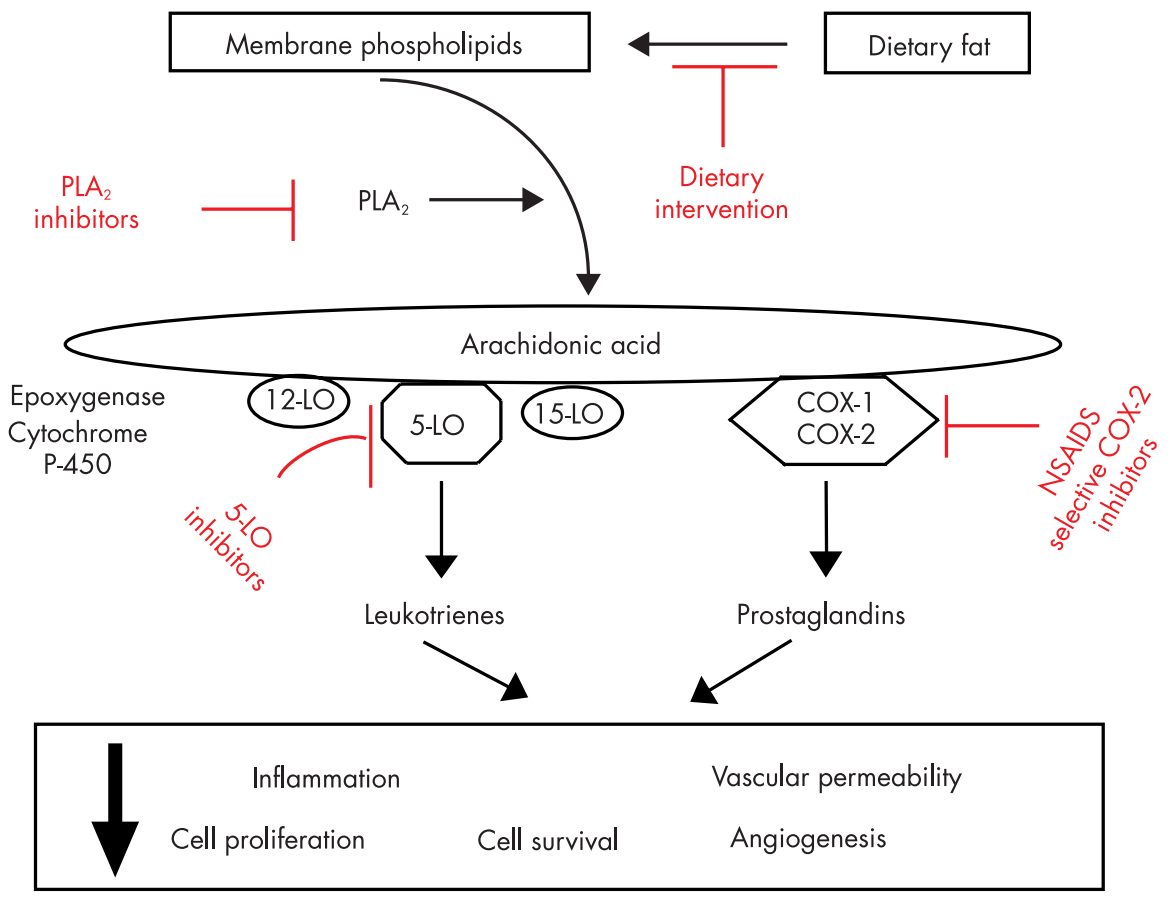

Figure 1 Arachidonic acid (AA) metabolism. Brain tumour cells contain abnormally high concentrations of two dietary polyunsaturated fatty acids, $A A$ and linoleic acid. AA is biosynthesised from dietary linoleic acid or is incorporated into membrane phospholipids directly from dietary AA. Activation of phospolipase $A_{2}$ (PLA $)$ causes the release of free AA. ${ }^{21}$ Once AA is released from phospholipids, it is oxidised by one of three different groups of oxygenases into AA metabolites eicosanoids. The insertion of a single oxygen atom into AA by certain cytochrome $\mathrm{P}$ - 450 enzymes produces epoxy-AA. Cyclooxygenases (COXs) introduce two molecules of oxygen into AA, and prostaglandins, thromboxanes, prostacyclin, and malondialdehyde are synthesised through a series of subsequent biochemical steps. COX-1 is a constitutively active enzyme present in most cell types, whereas COX-2 is almost undetectable in most unstimulated tissues. ${ }^{10}$ However, the expression and activity of COX-2 is inducible and regulated by a variety of ligands, including growth factors, Ras proteins, cytokines, and tumour promoters. ${ }^{10}$ Lipoxygenases (LOs) introduce one molecule of oxygen into $A A$ to produce a series of isomeric hydroperoxy acids that are subsequently converted into leukotrienes and lipoxins. According to the positional specificity with respect to AA, mammalian lipoxygenases are categorised into three main groups, 5-LO, 12-LO, and 15-LO. 5-LO performs the first of two enzymatic reactions in the biosynthetic pathway for the leukotrienes. ${ }^{11} \mathrm{COX}$ and 5-LO derived eicosanoids stimulate cell proliferation, survival, adhesion, and motility, in addition to angiogenesis, increased vascular permeability, and inflammation, thus playing important roles in tumour growth and promotion. ${ }^{12-20}$ They are also considered to be the main mediators of peritumorous brain oedema in patients with glioblastoma multiforme..$^{19} 20$ Tumorigenesis associated cellular functions of eicosanoids can be inhibited by the suppression of PLA ${ }_{2}$ activity, ${ }_{1}^{21-23}$ by cyclooxygenase inhibitors such as non-steroidal anti-inflammatory drugs (NSAIDs) and COX-2 specific inhibitors, ${ }^{10}{ }^{24}{ }^{25}$ by 5 -LO inhibitors such as boswellic acids, ${ }^{26-29}$ and possibly by the reduced dietary intake of $\omega-6$ linoleic and arachidonic acid and increased intake of $\omega-3$ polyunsaturated fattly acids. ${ }^{30-33}$ 
Nebraska, ${ }^{43}$ whereas increased consumption of total fat and cholesterol was found to be inversely associated with glioma risk in Israel. ${ }^{44}$

Even if people who develop gliomas and meningiomas do not have a higher intake of AA and LA, it is possible that molecular changes in these tumours may lead to more efficient accumulation of these PUFAs in the tumour tissue in the presence of a normal dietary intake. For example, increased expression of fatty acid-CoA ligase 4, an enzyme that uses AA preferentially as a substrate for esterification into membrane phospholipids, was found in adenocarcinomas of the colon compared with normal tissue. ${ }^{45}$ However, it remains to be determined whether similar molecular changes occur in brain tumours. Another reason why brain tumours contain raised concentrations of PUFAs may be that these tumours do not contain enzymes that would oxidise AA into eicosanoids. However, as described below, a large body of evidence does not support such an idea.

\section{"Phospholipase $A_{2}$ is the key enzyme involved in the initiation of the entire eicosanoid cascade because it releases free arachidonic acid from the $s n-2$ position of membrane phospholipids"}

Although $\omega-6$ fatty acids are abundant in the membrane phospholipids of brain tumour cells, only free unesterified fatty acids that are released from the membrane phospholipids can be metabolised into eicosanoids. Intracellular concentrations of free AA are low, so that its formation limits the synthesis of eicosanoids. Phospholipase $\mathrm{A}_{2}\left(\mathrm{PLA}_{2}\right)$ is the key enzyme involved in the initiation of the entire eicosanoid cascade because it releases free AA from the $s n-2$ position of membrane phospholipids. Although mammalian cells normally contain more than 12 members of the PLA group of enzymes, ${ }^{21}$ very limited information exists about $\mathrm{PLA}_{2}$ enzymes in human brain tumours. The expression and enzymatic activity of the calcium sensitive cytosolic $\mathrm{PLA}_{2}$ has been reported in normal human astrocytes, human astrocytoma cell lines $1321 \mathrm{Nl}$ and UC-11 MG, but not in U-373 MG cells. ${ }^{46}{ }^{47}$ Low amounts of the secreted form of $\mathrm{PLA}_{2}$ and low enzymic activity were detected in normal rat astrocyte cell cultures and were dramatically induced by proinflammatory stimuli such as tumour necrosis factor $\alpha^{48}$ To our knowledge, the expression of other types of $\mathrm{PLA}_{2}$ enzymes has not been reported in gliomas and meningiomas. Inhibition of $\mathrm{PLA}_{2}$ by non-specific $\mathrm{PLA}_{2}$ agents (4-bromophenacylbromide and quinacrine) suppressed the proliferation of primary meningioma cell cultures and the established human astrocytoma cell line, U373 MG, and these effects were partially reversed by the addition of exogenous $\mathrm{AA}^{49}$ These findings suggest that $\mathrm{PLA}_{2}$ activity may be important for glioma and meningioma cell proliferation.

\section{INCREASED EXPRESSION OF EICOSANOID PRODUCING ENZYMES IN GBM AND MENINGIOMA Cyclooxygenase}

The crucial role of COX eicosanoids has been clearly demonstrated in human colon cancer, in which COX-2 is often overexpressed. COX inhibitors, such as non-steroidal anti-inflammatory drugs and COX-2 specific inhibitors, can reduce the incidence of colorectal cancer in humans and experimental animals, and can decrease the polyp number and size in patients with familial adenomatous polyposis. ${ }^{50} \mathrm{In}$ addition to colon cancer, COX-2 is overexpressed in a spectrum of human malignancies, such as cancer of the breast, $^{51}{ }^{52}$ prostate, ${ }^{53}$ pancreas, ${ }^{5455}$ oesophagus, ${ }^{56}$ skin, ${ }^{57} 58$ and lung. ${ }^{59}$
Recently, gliomas and meningiomas were also found to overexpress both COX and lipoxygenase enzymes compared with normal brain tissue. Overexpression of both COX-1 and COX-2 enzymes was recently documented in human gliomas. ${ }^{60-65}$ In astrocytic gliomas, COX-1 was predominantly expressed in macrophages/microglial cells of the tumour mass, whereas COX-2 expression was mostly found in tumour cells and in single macrophages/microglial cells in perinecrotic areas. ${ }^{64} \mathrm{COX}-2$ expression was shown to correlate with the pathological grade ${ }^{61}$ and proliferation rate of gliomas. ${ }^{60}$ However, Matsuo et al reported that the staining intensity of GBM was relatively weak, but that astrocytomas (grades II and III) and meningiomas were strongly positive for COX-2. ${ }^{65}$ Shono et al found that patients with glioma who had the highest expression of COX-2 had the shortest survival. COX-2 was identified as the strongest predictor of outcome, independent of all other variables examined. ${ }^{63}$

A differential accumulation of COX isoforms during oligodendroglial tumour progression has also been recorded, with higher COX-1 expression in tumour cells of those patients whose tumours have "upgraded" to a more malignant phenotype. ${ }^{64}$ Both survival and the time to tumour progression were longer in those patients with a low COX-1 labelling score compared with patients whose tumours displayed high COX-1 expression. Oligodendroglial tumours, in particular the anaplastic variant that recurred, expressed a higher number of COX-2 positive cells (mostly neurones and astrocytes) than did healthy control brains. Oligodendroglioma COX-2 protein expression was also examined in our laboratories by Castilla et al. In this study, the predominant COX-2 staining was not attributable to macrophages/microglial cells or reactive astrocytes but rather to tumour cells. In addition, COX-2 immunoreactivity was associated with decreased patient survival, along with retention of chromosome $1 p$ and a high MIB-1 labelling index, whereas negative immunoreactivity for COX-2 and allelic loss of chromosome $1 p$ correlated with better survival. ${ }^{65 a}$

\section{5-Lipoxygenase}

Although much attention has been focused on the role of COX derived metabolites in cancer development and progression, accumulating evidence suggests that 5-LO derived eicosanoids may play equally important roles. 5-LO mRNA and/or protein was found to be overexpressed in human lung, ${ }^{66}$ prostate, ${ }^{67}$ pancreatic, ${ }^{68}$ and colon cancers. ${ }^{69}$ Boado et al reported increased expression of 5-LO mRNA in three of three GBM and three of three meningioma surgical specimens examined. The increase in 5-LO mRNA was greater in the GBM samples than in the meningiomas. ${ }^{70}$

Recent work from our laboratory suggested that surgical specimens of high grade astrocytomas and meningiomas overexpress 5-LO. Immunohistochemical analysis of surgical astrocytoma specimens shows that tumour cells and infiltrating macrophages/microglial cells express high amounts of 5-LO protein. In contrast, little if any 5-LO staining is detected in non-tumorous white matter control tissue. In addition, high amounts of both 5-LO mRNA and protein were expressed in some established GBM cell lines and a primary GBM cell culture. Staining for 5-LO was significantly more frequent in high grade than in low grade tumours ( $\mathrm{N}$ Nathoo et al, unpublished data).

\section{"Recent work from our laboratory suggested that surgical specimens of high grade astrocytomas and meningiomas overexpress 5-lipoxygenase"}

We also detected high expression of 5-LO in primary meningioma cells and meningioma surgical specimens by 
immunoblotting analysis. ${ }^{71}$ To date, it is unclear whether high 5-LO expression is present in meningioma precursor (leptomeningeal) cells or is a characteristic only of meningiomas. These data indicate that 5 - $\mathrm{LO}$ is overexpressed in high grade astrocytomas and possibly in meningiomas and support the notion that, in addition to COX-2 derived eicosanoids, 5-LO eicosanoids may also play a role in tumorigenesis and progression of these brain tumours.

\section{ENHANCED PRODUCTION OF EICOSANOIDS IN GLIOMAS AND MENINGIOMAS}

The existence of high concentrations of COX and 5-LO enzymes and their substrate (AA) in glioma and meningioma cells creates a favourable environment for the efficient production of eicosanoids. Therefore, it is not surprising that cultured meningioma and glioma cells produce high amounts of prostaglandins, thromoboxanes, and leukotrienes compared with normal brain tissue. ${ }^{72-76}$ AA metabolism capacity correlated well with proliferation patterns in neuroepithelial tumours, ${ }^{77}$ and was shown to be related to steroid receptors in certain brain tumours; that is, some metabolites of AA were produced in different amounts in brain tumours, which either did or did not express steroid receptors. ${ }^{78}$

In addition to in vitro production, eicosanoids can be detected systemically in patients with brain tumours, and their concentrations have been reported to decrease following neurosurgical resection or after treatment with specific inhibitors. ${ }^{73} 7980$ In a recent clinical study, patients with malignant brain tumours (GBM, anaplastic astrocytoma, malignant meningioma, and medulloblastoma) had significantly higher concentrations of prostaglandin $\mathrm{E}_{2}\left(\mathrm{PGE}_{2}\right)$ in their plasma than did patients with benign brain tumours (meningiomas and pituitary adenomas), metastatic brain tumours, or non-tumorous control patients. ${ }^{79}$ The high concentrations of $\mathrm{PGE}_{2}$ decreased significantly (by a factor of three) three days after surgical removal of both malignant and benign brain tumours. Simmet et al detected high concentrations of leukotriene $\mathrm{E}_{4}$ in the urine of eight patients with GBM. ${ }^{73}$ The values dropped by $80 \%$ within seven days of surgical removal of the tumour. In contrast, five patients with meningiomas excreted less leukotriene $\mathrm{E}_{4}$ and the values did not change significantly following meningioma removal. These data suggest that malignant brain tissue is the source of raised systemic COX and 5-LO derived eicosanoids.

\section{"The use of cyclooxygenase 2 and 5- lipoxygenase inhibitors may even be an alternative to glucocorticoids for the treatment of eicosanoid induced peritumorous brain oedema"}

Of particular importance is the observation that eicosanoids, produced by brain tumour cells, probably cause the development of tumour induced brain oedema. ${ }^{19} 20$ Peritumorous brain oedema is frequently found in both gliomas and meningiomas, and can contribute to the morbidity of patients with brain tumours. Glucocorticoids (such as dexamethasone) are used to treat peritumorous brain oedema. Although glucocorticoids often provide dramatic symptomatic relief for patients, they have many undesirable side effects. ${ }^{81}$

Of particular concern is the possibility that glucocorticoids may attenuate the cytotoxic effects of chemotherapy. ${ }^{82-85}$ For example, they activate the human $O^{6}$-methylguanine DNA methyltransferase gene. ${ }^{85}$ The product of this gene functions as a DNA repair protein that removes the mutagenic DNA adduct $O^{6}$-alkylguanine, which is generated after exposure to alkylating antitumour drugs, such as those used for chemotherapy of GBM.
A substantial part of the beneficial effects of glucocorticoids in reducing oedema results from the suppression of $\mathrm{PLA}_{2}$ activity and the reduction of free AA, in addition to inhibition of COX-2. ${ }^{22}$ However, there are reports suggesting that glucocorticoids upregulate the expression of 5-LO in rat neurones, human monocytes, and mast cells. ${ }^{86-88}$ Although the effects of glucocorticoids on 5-LO expression in vivo are unknown, these observations may have important therapeutic applications. These findings suggest that glucocorticoids and 5-LO inhibitors would have additive clinical benefits, and the use of COX-2 and 5-LO inhibitors may even be an alternative to glucocorticoids for the treatment of eicosanoid induced peritumorous brain oedema.

\section{EICOSANOID INHIBITORS}

An additional line of evidence supporting the concept that the COX-1, COX-2, and 5-LO proteins are involved in the tumorigenesis of gliomas and meningiomas comes from studies using COX and 5-LO inhibitors. Non-selective COX inhibitors, such as acetylsalicylic acid (aspirin), indomethacin, flurbiprofen, sulindac, and piroxicam, inhibited the growth of rat glioma cells both in vitro and in vivo, ${ }^{89}$ and several human glioma cells in vitro. ${ }^{62} 9091$ The COX-2 specific inhibitor NS-398 suppressed the proliferation of monolayer U-87 MG, U-251 MG human glioblastoma cell lines and the growth of three dimensional spheroids in vitro. In addition, NS-398 suppressed tumour cell migration and increased apoptotic cell death in spheroids. ${ }^{61}$ Another selective COX-2 inhibitor SC-236 was shown to be as effective as dexamethasone in extending the survival of rats implanted intracerebrally with 9L gliosarcoma cells, ${ }^{92}$ and to slow the tumour growth rate in nude mice with human U251 glioblastoma xenografts implanted in the hind leg. ${ }^{93}$

These data suggest that gliomas and meningiomas should be added to the growing list of human malignancies that are considered suitable for treatment with COX-2 inhibitors. ${ }^{51-59} 94$ Malignant gliomas are resistant to radiotherapy and chemotherapy; therefore, selective COX-2 inhibitors are currently being examined in combination with these standard therapeutic modalities ${ }^{95}$. The rationale for these combination modality clinical trials comes from studies that reported the enhancing effect of a selective COX-2 inhibitor SC-236 on the tumour response to radiotherapy in a murine model using sarcoma and human U251 glioblastoma cell lines. ${ }^{93}{ }^{96}$ Therefore, in the future the clinical use of COX-2 inhibitors may contribute to more efficient treatment for brain tumours.

Malignant gliomas are highly infiltrative tumours and this invasive nature represents a major obstacle to their effective treatment. Recent results obtained with inhibitors of thromboxane synthase suggest a novel anti-invasive approach for the treatment of gliomas. ${ }^{97}$ Thromboxane synthase converts COX derived $\mathrm{PGH}_{2}$ into thromboxane $\mathrm{A}_{2}$ and it was found to be overexpressed in highly migratory subpopulations of glioma cells. ${ }^{98}$ Specific thromboxane synthase inhibitors, such as furegrelate and dazmegrel, inhibited glioma cell migration and induced the apoptosis of these cells. ${ }^{62}$ When furegrelate was combined with camptothecin, it exerted a strong synergistic effect on the induction of apoptosis in glioma cells. ${ }^{62}$ Thus, further elucidation of the molecular mechanisms by which eicosanoids regulate glioma invasion will probably result in new ways to alter the migration and invasion of glioma cells and/or to increase their sensitivity to chemotherapeutic agents.

Boswellic acids, naturally occurring 5-LO inhibitors from the gum resin exudate of Boswellia serrata (frankincense), are known to kill meningioma and GBM cells in vitro by the induction of apoptosis. ${ }^{17} 71$ 99-101 In a rodent glioma model, the gum resin exudate of $B$ serrata decreased glioma volume, 
enhanced apoptosis, and more than doubled the survival time of treated rats compared with non-treated animals. ${ }^{100}$ The effects of frankincense derived boswellic acids were examined in two other small studies of patients with gliomas. Boeker and Winking treated 29 patients with glioma using the $\mathrm{H} 15$ herbal preparation containing a gum resin exudate of $B$ serrata for seven days. ${ }^{26}$ There was no effect on tumour size, but a significant reduction of peritumorous brain oedema with a concurrent improvement of the clinical condition was recorded. Streffer et al treated 11 patients with glioma (including seven patients with GBM) and progressive peritumorous brain oedema with the H15 preparation, and saw a radiological and/or clinical response to treatment in three patients with GBM. ${ }^{27}$

\section{CURRENT LIMITATIONS AND FUTURE PERSPECTIVES}

Investigations into the possible role of eicosanoids in the development and progression of brain tumours have progressed rapidly in the past few years. Today, specific inhibitors of eicosanoid pathways are being investigated in clinical trials of brain tumours. Nevertheless, many important questions remain unanswered.

Both benign meningiomas and GBMs contain raised amounts of AA and other $\omega-6$ PUFAs, and express high amounts of COX-2 and 5-LO enzymes with active production of eicosanoids. If eicosanoids do indeed play an important role in the tumorigenesis of these tumours, it remains to be determined whether additional molecular changes in eicosanoid cascades or those unrelated to AA metabolism are responsible for such distinct biological behaviour. For example, it is not known which of the many PLA $_{2}$ enzymes are expressed and functionally active in brain tumour cells. Little is known about the expression of a variety of PG and leukotriene receptors and other eicosanoid enzymes, such as 12-LO, 15-LO, and cytochrome P450 enzymes in brain tumours. This is an important gap in our current knowledge because several specific prostaglandin and leukotriene receptor antagonists are presently available for non-tumour related clinical use. ${ }^{102}$ In addition, although the 12-LO pathway may be an important procarcinogenic cell regulator, ${ }^{103} 104$ 15-LO eicosanoids probably mediate the anticarcinogenic effects of PUFAs. ${ }^{103} 105$ The reasons for the existence of an unbalanced profile of fatty acids in brain tumour cells (accumulation of $\omega-6$ and reduced amounts of $\omega-3$ PUFAs) needs to be further elucidated. If dietary fatty acid intake is responsible, restoration of the equilibrium by dietary means in patients with brain tumours should be investigated.

Dietary fatty acids were shown to increase the expression of eicosanoid producing enzymes, such as COX-2, ${ }^{106}{ }^{107}$ but they may modulate the growth and survival of brain tumour cells without their oxidation into eicosanoids. A family of steroid hormone receptors, peroxisome proliferator activated receptors, are activated not only by fatty acid metabolites but by dietary fatty acids themselves, and thus may provide a missing link between dietary fatty acids and cancer. ${ }^{108} 109$ Peroxisome proliferator activated receptor modulators are currently available for non-tumour related clinical use and are likely to stimulate investigations by brain tumour researchers in this rapidly growing field. ${ }^{108} 110$

The tumour suppressive effects of COX and LO inhibitors may not only be related to the reduction in the production of eicosanoids, but they may also increase cellular concentrations of unesterified AA and induce the apoptosis of cancer cells. $^{111} 112$ In other words, aberrantly raised expression of eicosanoid producing enzymes in tumour cells may promote tumorigenesis by increasing the intracellular utilisation of AA, thus suppressing unesterified AA mediated apoptosis. There is increasing evidence that polyunsaturated fatty acids, such as $\gamma$ linolenic, arachidonic, and eicosapentaenoic acids induce cell death and apoptosis of a variety of human cancer cell lines, including glioma cells, but not "normal" nontumorigenic cells. ${ }^{113-116}$ However, the effects on cancer cells may depend on the concentration of exogenously added fatty acid. For example, $\gamma$ linolenic acid impaired the growth of glioma spheroids only at concentrations higher than $100 \mu \mathrm{M}$, whereas lower concentrations stimulated tumour cell growth and invasion. ${ }^{115}$ The cytotoxic action of PUFAs may be mediated through lipid peroxidation and free radical generation, ${ }^{117}$ in addition to AA stimulated conversion of sphingomyelin to the apoptosis inducer ceramide. ${ }^{112}$ Intratumorous infusion of PUFAs in a rodent glioma model resulted in increased apoptosis and regression of tumour growth. ${ }^{118}$ Some improvements were documented in patients with malignant gliomas in whom $\gamma$ linolenic acid was administered via a cerebral reservoir placed in the tumour bed or by direct intratumorous delivery. ${ }^{119}{ }^{120}$ This treatment was found to be safe, but it remains to be determined whether higher concentrations of $\gamma$ linolenic acid (or other PUFAs) and a longer duration of treatment alone or in combination with radiotherapy would result in better outcomes.

\section{"Aberrantly raised expression of eicosanoid producing enzymes in tumour cells may promote tumorigenesis by increasing the intracellular utilisation of arachidonic acid (AA), thus suppressing unesterified AA mediated apoptosis"}

Although the available evidence supports the idea that COX-2 and 5-LO proteins are aberrantly overexpressed and enzymatically active in gliomas and meningiomas, the data are less consistent with regard to the degree of staining and the nature of the cells that stain with specific antibodies. Previous investigators have used various antibodies, making it difficult to compare the results from different studies. Clearly, the use of specific antibodies directed against eicosanoid producing enzymes should be standardised so that the staining information can be used for clinical purposes, particularly those related to clinical trials with specific eicosanoid inhibitors. An additional concern when interpreting the COX-2 and 5-LO expression data is the possibility that upregulation of COX-2 and 5-LO in brain tumours may be partly caused by hypoxia introduced during and after tumour removal. Some studies suggest that hypoxia may induce both COX-2 $2^{121}$ and $5-\mathrm{LO}^{122}$ expression.

Although glucocorticoids, used to treat peritumorous brain oedema, may reduce the effectiveness of chemotherapy and radiotherapy, COX-2 inhibitors may in fact enhance these treatments, and combination trials with patients with brain tumours are currently in progress..$^{95}$ Further investigations are needed to establish whether COX-2 and 5-LO inhibitors can reduce peritumorous brain oedema in patients with brain tumours as effectively as glucocorticoids, but with less side effects. Selective COX-2 inhibitors were until recently considered to have fewer gastrointestinal adverse effects than non-selective, non-steroidal anti-inflammatory drugs. However, this premise is debatable because flaws in trial design and reporting of results cast doubts on the gastrointestinal, cardiovascular, and global safety profile of COX-2 specific inhibitors. ${ }^{24}{ }^{123}$ Nevertheless, if effective for oedema reduction, these inhibitors will probably have fewer side effects than glucocorticoids. It remains to be determined whether the use of a combination of COX-2 and 5-LO inhibitors would be more effective than the use of either drug alone. 


\section{Take home messages}

- The two most common types of human brain tumour, gliomas and meningiomas, overexpress eicosanoid producing enzymes, cyclooxygenases (COX-1 and COX-2) and lipoxygenases (5-LO, 12-LO, and 15LO), and release a spectrum of eicosanoids that may promote tumorigenesis and the development of peritumorous brain oedema

- COX-2 and 5-LO inhibitors may be useful for the treatment of patients with malignant brain tumours, and they are currently under investigation in clinical trials

- Current and newer agents that specifically target key players of the eicosanoid cascade could change the approach to treating brain tumours, because their benefits may lie in their synergism with conventional cytotoxic treatments and/or with other novel agents targeted against other procarcinogenic pathways

- Further research is needed because the precise role of the eicosanoid cascade in the tumorigenesis of human brain tumours is still unclear

\section{CONCLUSIONS}

A new era of targeted treatments is rapidly evolving. The accrual of knowledge relating to the molecular pathways that govern the fundamental mechanisms of cell growth and survival, and how these pathways are altered in cancer, may be the key to improving patient survival and outcome from cancer in general, and particularly for patients with malignant gliomas. The downregulation or inhibition of tumour promoting eicosanoid cascades may represent one additional method of effectively and safely preventing and treating human brain tumours.

\section{ACKNOWLEDGEMENTS}

The authors would like to thank Ms M Tobin (Department of Neurosurgery) for helping to edit this manuscript.

\section{Authors' affiliations}

N Nathoo, G H Barnett, Brain Tumour Institute and Department of Neurosurgery, Cleveland Clinic Foundation, Cleveland, 44195 Ohio, USA M Golubic, Brain Tumor Institute, Cleveland Clinic Foundation

\section{REFERENCES}

1 Jemal A, Murray T, Samuels A, et al. Cancer statistics, 2003. CA Cancer J Clin 2003;53:5-26.

2 Wrensch $M$, Minn Y, Chew T, et al. Epidemiology of primary brain tumors: current concepts and review of the literature. Neuro-oncology 2002;4:278-99.

3 Kleihues P, Soylemezoglu F, Schauble B, et al. Histopathology, classification, and grading of gliomas. Glia 1995;15:21 1-21.

4 Maher EA, Furnari FB, Bachoo RM, et al. Malignant glioma: genetics and biology of grave matter. Genes Dev 2001;15:1311-33.

5 Russel DS, Rubinstein $\amalg$. Tumours of the meninges and related tissues. In: Russel DS, Rubinstein $\sqcup$, eds. Pathology of tumours of the nervous system. Baltimore: Williams \& Wilkins, 1989:449-532.

6 Kujas M. Meningioma. Curr Opin Neurol Neurosurg 1993;6:882-7.

7 Funk CD. Prostaglandins and leukotrienes: advances in eicosanoid biology. Science $2001 ; 294: 1871-5$.

8 Soberman RJ, Christmas P. The organization and consequences of eicosanoid signaling. J Clin Invest 2003;111:1107-13.

9 Smith WL, Garavito M, DeWitt DL. Prostaglandin endoperoxide $\mathrm{H}$ synthases (cyclooxygenases)-1 and -2. J Biol Chem 1996;271:33157-60.

10 Turini ME, DuBois RN. Cyclooxygenase-2: a therapeutic target. Annu Rev Med 2002;53:35-57.

11 Ford-Hutchinson AW. Regulation of leukotriene synthesis. Cancer Metastasis Rev 1994; 13:257-67.

12 Romano M, Catalano A, Nutini M, et al. 5-Lipoxygenase regulates malignant mesothelioma cell survival: involvement of vascular endothelial growth factor. FASEB J 2001;15:2326-36.
13 Tong WG, Ding XZ, Witt RC, et al. Lipoxygenase inhibitors attenuate growth of human pancreatic cancer xenografts and induce apoptosis through the mitochondrial pathway. Mol Cancer Ther 2002;1:929-35.

14 Tsujii M, DuBois RN. Alterations in cellular adhesion and apoptosis in epithelial cells overexpressing prostaglandin endoperoxide synthase 2. Cell 1995;83:493-501

15 Peppelenbosch MP, Tertoolen LG, Hage WJ, et al. Epidermal growth factorinduced actin remodeling is regulated by 5 -lipoxygenase and cyclooxygenase products. Cell 1993;74:565-75.

16 Capodici C, Pillinger MH, Han G, et al. Integrin-dependent homotypic adhesion of neutrophils. Arachidonic acid activates Raf-1/Mek/Erk via a 5-lipoxygenase-dependent pathway. J Clin Invest 1998;102:165-75.

17 Park YS, Lee JH, Bondar J, et al. Frankincense-derived boswellic acids inhibi growth and motility of brain tumor cells [abstract]. Complement Ther Med 2002;10:117-18.

18 Tsujii M, Kawano S, Tsuji S, et al. Cyclooxygenase regulates angiogenesis induced by colon cancer cells. Cell 1998;93:705-16.

19 Constantini S, Tamir J, Gomori MJ, et al. Tumor prostaglandin levels correlate with edema around supratentorial meningiomas. Neurosurgery 1993;33:204-10.

20 Black KL, Hoff JT, McGillicuddy JE, et al. Increased leukotriene $\mathrm{C}_{4}$ and vasogenic edema surrounding brain tumors in humans. Ann Neurol $1986 ; 19: 592-5$

21 Balsinde J, Balboa MA, Insel PA, et al. Regulation and inhibition of phospholipase A2. Annu Rev Pharmacol Toxicol 1999;39:175-89.

22 Goppelt-Struebe M. Molecular mechanisms involved in the regulation of prostaglandin biosynthesis by glucocorticoids. Biochem Pharmacol 1997;53:1389-95.

23 Burke JR, Witmer MR, Zusi C, et al. Competitive, reversible inhibition of cytosolic phospholipase $A_{2}$ at the lipid-water interface by choline derivatives that partially partition into the phospholipid bilayer. J Biol Chem 1999;274:18864-71.

24 Wright JM. The double-edged sword of COX-2 selective NSAIDs. Can Med Assoc J 2002:167:1131-7.

25 Hong SH, Avis I, Vos MD, et al. Relationship of arachidonic acid metabolizing enzyme expression in epithelial cancer cell lines to the growth effect of selective biochemical inhibitors. Cancer Res 1999;59:2223-8.

26 Boeker DK, Winking M. Die Rolle von Boswellia-Sauren in der Therapie maligner Gliome. Dtsch Arztebl 1997:94:A1 197-9.

27 Streffer JR, Bitzer M, Schabet $M$, et al. Response of radiochemotherapyassociated cerebral edema to a phytotherapeutic agent, H15. Neurology 2001;56:1219-21

28 Steele VE, Holmes CA, Hawk ET, et al. Lipoxygenase inhibitors as potential cancer chemopreventives. Cancer Epidemiol Biomarkers Prev 1999;8:467-83

29 Safayhi H, Mack T, Sabieraj J, et al. Boswellic acids: novel, specific, nonredox inhibitors of 5-lipoxygenase. J Pharmacol Exp Ther 1992;261:1143-6.

30 Lai LTY, German B. Modulation of fatty acid composition in murine brain by dietary unsaturated fats. J Nutr Biochem 1993;4:463-71.

31 Clandinin MT, Cheema S, Field CJ, et al. Dietary fat: exogenous determination of membrane structure and cell function. FASEB $J$ 1991;5:2761-9.

32 Blair IA, Prakash C, Phillips MA, et al. Dietary modification of omega- 6 fatty acid intake and its effect on urinary eicosanoid excretion. Am J Clin Nutr 1993:57:154-60.

33 James MJ, Gibson RA, Cleland LG. Dietary polyunsaturated fatty acids and inflammatory mediator production. Am J Clin Nutr 2000;71(suppl):343S-8S

34 Ledwozyw A, Lutnicki K. Phospholipids and fatty acids in human brain tumors. Acta Physiol Hung 1992;79:381-7.

35 Martin DD, Robbins MEC, Spector AA, et al. The fatty acid composition of human gliomas differs from that found in nonmalignant brain tissue. Lipids 1996:31:1283-8

36 Kokoglu E, Tuter Y, Yazici Z, et al. Profiles of the fatty acids in the plasma membrane of human brain tumors. Cancer Biochem Biophys 1998;16:301-12.

37 Sinclair HM. Essential fatty acids - an historical perspective. Biochem Soc Trans 1990;18:756-61.

38 German BJ, Dillard CJ, Whelan J. Introduction to symposium: biological effects of dietary arachidonic acid. J Nutr 1995; 126:1076S-80S.

39 Taber L, Chiu C-H, Whelan J. Assessment of the arachidonic acid content in foods commonly consumed in the American diet. Lipids 1998:33:1151-7.

40 Nariai T, Greig NH, DeGeorge JJ, et al. Intravenously injected radiolabelled fatty acids image brain tumor phospholipids in vivo: differential uptakes of palmitate, arachidonate and docosohexaenoate. Clin Exp Metastasis 1993:11:141-9.

41 Giles GG, McNeil JJ, Donnan G, et al. Dietary factors and the risk of glioma in adults: results of a case-control study in Melbourne, Australia. Int J Cancer 1994;59:357-62

42 Lubin F, Farbstein $\mathrm{H}$, Chetrit $\mathrm{A}$, et al. The role of nutritional habits during gestation and child life in pediatric brain tumor etiology. Int J Cancer 2000;86: 139-43

43 Chen $\mathrm{H}$, Ward $\mathrm{MH}$, Tucker $\mathrm{KL}$, et al. Diet and risk of adult glioma in eastern Nebraska, United States. Cancer Causes Control 2002;13:647-55.

44 Kaplan S, Novikov I, Modan B. Nutritional factors in the etiology of brain tumors: potential role of nitrosamines, fat, and cholesterol. Am J Epidemiol 1997; 146:832-41.

45 Cao Y, Dave KB, Doan TP, et al. Fatty acid CoA ligase 4 is up-regulated in colon adenocarcinoma. Cancer Res 2001;61:8429-34. 
46 Stephenson DT, Manetta JV, White DL, et al. Calcium-sensitive cytosolic phospholipase A2 (cPLA2) is expressed in human brain astrocytes. Brain Res 1994;637:97-105.

47 Hernandez M, Burillo SL, Crespo MS, et al. Secretory phospholipase A2 activates the cascade of mitogen-activated protein kinases and cytosolic phospholipase A2 in the human astrocytoma cell line 1321N1. J Biol Chem 1998;273:606-12.

48 Oka S, Arita H. Inflammatory factors stimulate expression of group II phospholipase A2 in rat cultured astrocytes. Two distinct pathways of the gene expression. J Biol Chem 1991;266:9956-60.

49 Petr M, Origitano T, Wurster R. PLA 2 Activity regulates $\mathrm{Ca}^{++}$storagedependent cellular proliferation. Exp Cell Res 1998;244:310-18.

50 Gupta RA, Dubois RN. Colorectal cancer prevention and treatment by inhibition of cyclooxygenase-2. Nat Rev Cancer 2001;1:11-21.

51 Ristimaki A, Sivula A, Lundin J, et al. Prognostic significance of elevated cyclooxygenase-2 expression in breast cancer. Cancer Res 2002;62:632-5.

52 Soslow RA, Dannenberg AJ, Rush D, et al. COX-2 is expressed in human pulmonary, colonic, and mammary tumors. Cancer 2000;89:2637-45.

53 Gupta S, Srivastava M, Ahmad N, et al. Over-expression of cyclooxygenase- 2 in human prostate adenocarcinoma. Prostate 2000:42:73-8.

54 Tucker ON, Dannenberg AJ, Yang EK, et al. Cyclooxygenase- 2 expression is up-regulated in human pancreatic cancer. Cancer Res 1999;59:987-90.

55 Okami J, Yamamoto H, Fujiwara Y, et al. Overexpression of cyclooxygenase-2 in carcinoma of the pancreas. Clin Cancer Res 1999:5:2018-24

56 Zimmermann KC, Sarbia M, Weber AA, et al. Cyclooxygenase-2 expression in human esophageal carcinoma. Cancer Res 1999;59:198-204

57 Buckman SY, Gresham A, Hale P, et al. COX-2 expression is induced by UVB exposure in human skin: implications for the development of skin cancer. Carcinogenesis 1998; 19:723-9.

58 Higashi Y, Kanekura T, Kanzaki T. Enhanced expression of cyclooxygenase (COX)-2 in human skin epidermal cancer cells: evidence for growth suppression by inhibiting COX-2 expression. Int J Cancer 2000;86:667-71.

59 Ermert L, Dierkes C, Ermert M. Immunohistochemical expression of cyclooxygenase isoenzymes and downstream enzymes in human lung tumors. Clin Cancer Res 2003;9:1604-10.

60 Prayson RA, Castilla EA, Vogelbaum MA, et al. Cyclooxygenase-2 (COX-2) expression by immunohistochemistry in glioblastoma multiforme. Ann Diagn Pathol 2002;6:148-53.

61 Joki T, Heese O, Nikas DC, et al. Expression of cyclooxygenase 2 (COX-2) in human glioma and in vitro inhibition by a specific COX-2 inhibitor, NS-398. Cancer Res 2000;60:4926-31.

62 Kurzel F, Hagel Ch, Zapf S, et al. Cyclo-oxygenase inhibitors and thromboxane synthase inhibitors differentially regulate migration arrest, growth inhibition and apoptosis in human glioma cells. Acta Neurochir (Wien) 2002;144:71-87.

63 Shono T, Tofilon PJ, Bruner JM, et al. Cyclooxygenase-2 expression in human gliomas: prognostic significance and molecular correlations. Cancer Res 2001;61:4375-81.

64 Deininger MH, Meyermann R, Trautmann K, et al. Cyclooxygenase (COX)-1 expressing macrophages/microglial cells and COX-2 expressing astrocytes accumulate during oligodendroglioma progression. Brain Res 2000;885:111-16

65 Matsuo M, Yonemitsu N, Zaitsu M, et al. Expression of prostaglandin $\mathrm{H}$ synthase-2 in human brain tumors. Acta Neuropathol (Berl) 2001; 102:181-7.

65a Castilla EA, Prayson RA, Kanner AA, et al. Cyclooxygenase-2 in oligodendroglial neoplasms. Cancer 2003;98:1465-72.

66 Avis IM, Jett M, Boyle T, et al. Growth control of lung cancer by interruption of 5-lipoxygenase-mediated growth factor signaling. Clin Invest 1996;97:803-6.

67 Gupta S, Srivastava M, Ahmad N, et al. Lipoxygenase-5 is overexpressed in prostate adenocarcinoma. Cancer 2001;91:737-43.

68 Hennig R, Ding X, Tong W, et al. 5-Lipoxygenase and leukotriene B4 receptor are expressed in human pancreatic cancers but not in pancreatic ducts in normal tissue. Am J Pathol 2002:161:421-8.

69 Ohd JF, Nielsen CK, Campbell J, et al. Expression of the leukotriene D4 receptor CysLT1, COX-2, and other cell survival factors in colorectal adenocarcinomas. Gastroenterology 2003;124:57-70.

70 Boado RJ, Pardridge WM, Vinters HV, et al. Differential expression of arachidonate 5-lipoxgenase transcripts in human brain fumors: evidence for the expression of a multitranscript family. Proc Natl Acad Sci U S A 1992;89:9044-8.

71 Park YS, Lee JH, Harwalkar JA, et al. Acetyl-11-keto-beta-boswellic acid (AKBA) is cytotoxic for meningioma cells and inhibits phosphorylation of the extracellular-signal regulated kinase 1 and 2. Adv Exp Med Biol 2002;507:387-93.

72 Castelli MG, Chiabrando C, Fanelli R, et al. Prostaglandin and thromboxane synthesis by human intracranial tumors. Cancer Res 1989;49:1505-8.

73 Simmet $T$, Luck W, Winking $M$, et al. Identification and characterization of cysteinyl-leukotriene formation in tissue slices from human intracranial tumors: evidence for their biosynthesis under in vivo conditions. J Neurochem 1990;54:2091-9.

74 Inamura $T$, Abe $M$, Ikezaki $K$, et al. Leukotriene $C_{4}$ contents, synthase and catabolic activity in human meningiomas. Neurol Res 1992; 14:405-10.

75 Cooper C, Jones HG, Weller RO, et al. Production of prostaglandins and thromoboxane by isolated cells from intracranial tumors. J Neurol Neurosurg Pshychiatry 1984;47:579-84.
76 Kokoglu E, Tuter Y, Sandikci KS, et al. Prostaglandin $E_{2}$ levels in human brain tumor tissues and arachidonic acid levels in the plasma membranes of human brain tumors. Cancer Lett 1998;132:17-21.

77 Gaetani P, Butti G, Chiabrando C, et al. A study on the biological behavior of human brain tumors. Part I. Arachidonic acid metabolism and DNA content. J Neurooncol 1991;10:233-40.

78 Butti G, Gaetani P, Chiabrando C, et al. A study on the biological behavior of human brain tumors. Part II. Steroid receptors and arachidonic acid metabolism. J Neurooncol 1991;10:241-6.

79 Loh JK, Hwang SL, Lieu AS, et al. The alteration of prostaglandin $E_{2}$ levels in patients with brain tumors before and after tumor removal. J Neurooncol 2002;57:147-50.

80 Heldt RM, Winking M, Simmet T. Cysteinyl-leukotrienes as potential mediators of the peritumoral brain oedema in astrocytoma patients. Suppl to Naunyn-S [abstract]. Arch Pharmacol 1996;353:A538.

81 Frauman AG. An overview of the adverse reactions to adrenal corticosteroids. Adverse Drug React Toxicol Rev 1996;15:203-6.

82 Weller M, Schmidt C, Roth W, et al. Chemotherapy of human malignant glioma: prevention of efficacy by dexamethasone? Neurology 1997;48:1704-9.

83 Naumann U, Durka S, Weller M. Dexamethasone-mediated protection from drug cytotoxicity: association with $\mathrm{p} 21^{\mathrm{WAF} / \mathrm{CIP1}}$ protein accumulation? Oncogene 1998;17:1567-75.

84 Gorman AM, Hirt UA, Orrenius S, et al. Dexamethasone pre-treatment interferes with apoptotic death in glioma cells. Neurosicence 2000:96:417-25.

85 Biswas T, Ramana CV, Srinivasan G, et al. Activation of human $\mathrm{O}^{6}$. methylguanine-DNA methyltransferase gene by glucocorticoid hormone. Oncogene 1999;18:525-32.

86 Uz T, Swivedi Y, Savani PD, et al. Glucocorticoids stimulate inflammatory 5 -lipoxygenase gene expression and protein translocation in the brain. J Neurochem 1999;73:693-9.

87 Colamorea T, Di Paola R, Macchia F, et al. 5-Lipoxygenase upregulation by dexamethasone in human mast cells. Biochem Biophys Res Commun 1999;265:617-24.

88 Riddick CA, Ring WL, Baker JR, et al. Dexamethasone increases expression of 5 -lipoxygenase and its activating protein in human monocytes and THP-1 cells. Eur J Biochem 1997:246:112-18.

89 Aas AT, Tonnessen TI, Brun A, et al. Growth inhibition of rat glioma cells in vitro and in vivo by aspirin. J Neurooncol 1995;24:171-80.

90 Blomgren H, Kling-Andersson G. Growth inhibition of human malignant glioma cells in vitro by agents which interfere with the biosynthesis of eicosanoids. Anticancer Res 1992;12:981-6.

91 King JG Jr, Khalili K. Inhibition of human brain tumor cell growth by the antiinflammatory drug, flurbiprofen. Oncogene $2001 ; 20: 6864-70$.

92 Portnow J, Suleman S, Grossman SA, et al. A cyclooxygenase-2 (COX-2) inhibitor compared with dexamethasone in a survival study of rats with intracerebral 9L gliosarcomas. Neurooncol 2002;4:22-5.

93 Petersen C, Petersen S, Milas L, et al. Enhancement of intrinsic tumor cell radiosensitivity induced by a selective cyclooxygenase- 2 inhibitor. Clin Cancer Res 2000;6:2513-20.

94 Smigel K. Arthritis drug approved for polyp prevention blazes trail for other prevention trials. J Natl Cancer Inst 2000;92:297-9.

95 Pannullo S, Balmaceda C, Serventi J, et al. Temozolomide (Temodar ${ }^{\circledR}$ ) plus celecoxib (celebrex ${ }^{\circledR}$ ) for treatment of malignant gliomas [abstract]. Neurooncology 2002;4:A239.

96 Milas L, Kishi K, Hunter N, et al. Enhancement of tumor response to gammaradiation by an inhibitor of cyclooxygenase-2 enzyme. J Natl Cancer Inst 1999:91:1501-4.

97 Giese A, Bjerkvig R, Berens ME, et al. Cost of migration: invasion of malignant gliomas and implications for treatment. J Clin Oncol 2003;21:1624-36.

98 McDonough W, Tran N, Giese A, et al. Altered gene expression in human astrocytoma cells selected fro migration: I. Thromoboxane synthase. J Neuropathol Exp Neurol 1998;57:449-55.

99 Glaser T, Winter S, Groscurth P, et al. Boswellic acids and malignant glioma: induction of apoptosis but no modulation of drug sensitivity. Br J Cancer $1999 \cdot 80 \cdot 756-65$.

100 Winking M, Sarikaya S, Rahmanian A, et al. Boswellic acids inhibit glioma growth: a new treatment option? J Neurooncol 2000;46:97-103.

101 Park YS, Lee JH, Bondar J, et al. Cytotoxic action of acetyl-11-keto-betaboswellic acid (AKBA) on meningioma cells. Planta Med 2002;68:397-401

102 Peters SP. Leukotriene receptor antagonists in asthma therapy. J Allergy Clin Immunol 2003;111(suppl 1):S62-70.

103 Shureiqi I, Lippman SM. Lipoxygenase modulation to reverse carcinogenesis. Cancer Res 2001;61:6307-12.

104 Pidgeon GP, Kandouz M, Meram A, et al. Mechanisms controlling cell cycle arrest and induction of apoptosis after 12-lipoxygenase inhibition in prostate cancer cells. Cancer Res 2002;62:2721-7.

105 Shappell SB, Gupta RA, Manning S, et al. 15S-Hydroxyeicosatetraenoic acid activates peroxisome proliferator-activated receptor gamma and inhibits proliferation in PC 3 prostate carcinoma cells. Cancer Res 2001;61:497-503.

106 Badawi AF, El-Sohemy A, Stephen LL, et al. The effect of dietary n-3 and n-6 polyunsaturated fatty acids on the expression of cyclooxygenase 1 and 2 and levels of p21 ras in rat mammary glands. Carcinogenesis 1998; 19:905-10.

107 Rao CV, Hirose Y, Indranie C, et al. Modulation of experimental colon tumorigenesis by types and amounts of dietary fatty acids. Cancer Res 2001;61:1927-33. 
108 Kopelovich L, Fay JR, Glazer RI, et al. Peroxisome proliferator-activated receptor modulators as potential chemopreventive agents. Mol Cancer Ther 2002; 1:357-63.

109 Vanden Heuvel JP. Peroxisome proliferator-activated receptors: a critical link among fatty acids, gene expression and carcinogenesis. J Nutr 1999; 129:575S-80S.

110 Zander T, Kraus JA, Grommes C, et al. Induction of apoptosis in human and rat glioma by agonists of the nuclear receptor PPARgamma. J Neurochem 2002:81:1052-60

111 Cao Y, Pearman TA, Zimmerman GA, et al. Intracellular unesterified arachidonic acid signals apoptosis. Proc Natl Acad Sci U S A 2000;97:11 280-5

112 Chan TA, Morin PJ, Vogelstein B, et al. Mechanisms underlying nonsteroidal anti-inflammatory drug-mediated apoptosis. Proc Natl Acad Sci U S A 1998;95:681-6.

113 Begin ME, Sircar S, Weber JM. Differential sensitivity of tumorigenic and genetically related non-tumorigenic cells to cytotoxic polyunsaturated fatty acids. Anticancer Res 1989:9:1049-52.

114 Williams JR, Leaver HA, Ironside JW, et al. Apoptosis in human primary brain tumours: actions of arachidonic acid. Prostaglandins Leukot Essent Fatty Acids 1998;58:193-200.

115 Bell HS, Wharton SB, Leaver A, et al. Effects of N-6 essential fatty acids on glioma invasion and growth: experimental studies with glioma spheroids in collagen gels. J Neurosurg 1999;91:989-96.
116 Vartak S, McCaw R, Davis CS, et al. $\gamma$-Linolenic acid (GLA) is cytotoxic to 36 B 10 malignant rat astrocytoma cells but not to "normal" rat astrocytes. Br J Cancer 1998;77:1612-20.

117 Preuss M, Birnun GD, Darby CJ, et al. Role of antioxidant enzyme expression in the selective cytotoxic response of glioma cells to $\gamma$-linolenic acid supplementation. Free Radic Biol Med 2000;28:1143-56.

118 Leaver HA, Wharton SB, Bell HS, et al. Highly unsaturated fatty acid induced tumour regression in glioma pharmacodynamics and bioavailability of gamma linolenic acid in an implantation glioma model: effects on tumour biomass, apoptosis and neuronal tissue histology. Prostaglandins Leukot Essent Fatty Acids 2002;67:283-92.

119 Das UN, Prasad VVSK, Reddy DR. Local application of $\gamma$-linolenic acid in the treatment of human gliomas. Cancer Lett 1995;94:147-55.

120 Bakshi $H$, Mukherjee D, Backi $A$, et al. $\gamma$-Linolenic acid therapy of human gliomas. Nutrition 2003;19:305-9.

121 Schmedtie JF Jr, Ji YS, Liu WL, et al. Hypoxia induces cyclooxygenase-2 via the NF-kappaB p65 transcription factor in human vascular endothelial cells. $J$ Biol Chem 1997;272:601-8.

122 Tomimoto $\mathrm{H}$, Shibata $M$, Ihara $M$, et al. A comparative study on the expression of cyclooxygenase and 5-lipoxygenase during cerebral ischemia in humans. Acta Neuropathol (Berl) 2002;104:601-7.

123 Gomez Cerezo J, Lubomirov Hristov R, Carcas Sansuan AJ, et al. Outcome trials of COX-2 selective inhibitors: global safety evaluation does not promise benefits. Eur J Clin Pharmacol 2003:59:169-75.

\section{$\mathrm{ECHO}$}

Tissue grading system is a reliable assay of response to treatment in gastric MALT lymphoma

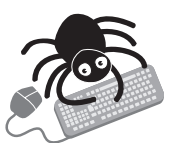

Please visit the Journal of Clinical Pathology website [www. jclinpath.com] for a link to the full text of this article. histological grading system for gastric MALT lymphoma after treatment looks to be a A promising tool for assessing residual disease in prospective drug trials. A pilot study has confirmed that the system has good internal reproducibility.

Good agreement was achieved among the scores of seven histopathologists who separately scored 45 sets of stained gastric biopsies for three criteria-lymphoid infiltrate, lymphoepithelial lesions, and stromal changes-from 10 patients treated for gastric MALT lymphoma. The results translated into four clinically meaningful scores: complete histological remission, probable minimal residual disease, responding residual disease, and no change.

The 10 patients comprised seven men and three women enrolled in one arm of a multicentre clinical trial of gastric MALT lymphoma and selected randomly. They had been treated to eradicate Helicobacter pylori and were followed up for a mean of 19 months, during which three to six sequential gastric biopsies were obtained. The histopathologists were blinded to the clinical results at follow up.

Gastric MALT lymphoma is closely associated with $H$ pylori gastric infection. Eradicating the infection usually clears up the cancer, but ensuring patients are clinically clear of the disease entails prolonged follow up. Histological evaluation of residual disease is difficult but remains the only indication for the time being. The present standardised system was devised to help judge the extent of residual disease. Further testing of this scoring system on more patients is the next step, but in time it may be a useful complement to molecular studies.

\ Gut 2003;52:1656. 